\title{
A High Proliferative Index of Recurrent Melanoma Is Associated with Worse Survival
}

\author{
Ting J. Tu ${ }^{a, b}$ Michelle W. Ma ${ }^{a, b}$ Stefano Monni ${ }^{f} \quad$ Amy E. Rose ${ }^{a, b}$ \\ Herman Yee ${ }^{a, c}$ Farbod Darvishian ${ }^{a, c}$ David Polsky ${ }^{a-c}$ Russell S. Berman ${ }^{a, d}$ \\ Richard L. Shapiro ${ }^{a, d}$ Anna C. Pavlick ${ }^{a, b, e}$ Madhu Mazumdar ${ }^{f}$ Iman Osman $^{a}$ b \\ ${ }^{a}$ The New York University Interdisciplinary Melanoma Cooperative Group, and Departments of bermatology, \\ cPathology, ${ }^{\mathrm{d}}$ Surgery and ${ }^{\mathrm{e}}$ Medicine, New York University School of Medicine, and ${ }^{\mathrm{f} D i v i s i o n}$ of Biostatistics and \\ Epidemiology, Department of Public Health, Weill Cornell Medical College, New York, N.Y., USA
}

\section{Key Words}

Melanoma $\cdot$ Prognosis $\cdot$ Recurrence $\cdot$ Ki-67 antigen •

Disease-free survival

\begin{abstract}
Objective: Previous melanoma studies evaluating prognostic factors of survival at recurrence have focused on primary tumor characteristics and clinical variables at first recurrence. We examined the prognostic relevance of recurrent tumor proliferation. Methods: 114 melanoma patients with available recurrent tissues who were prospectively enrolled at New York University Medical Center were studied. Standard of care prognostic variables (e.g. stage at initial diagnosis and lactate dehydrogenase level) and recurrent tissue expression of proliferative marker $\mathrm{Ki}-67$ were evaluated for their association with overall survival. Results: High Ki-67 expression was observed in 57 (50\%) of the 114 recurrent melanomas. On univariate analysis, the median overall survival of patients whose recurrent tumors overexpressed Ki-67 was significantly shorter than that of patients whose recurrent tumors had low Ki-67 expression (3.6 vs. 9.5 years, $p=0.03$ ). On multivariate analysis, a high proliferative index of the recurrent melanoma remained an independent predictor of
\end{abstract}

\section{KARGER}

(C) 2011 S. Karger AG, Basel

Fax +41613061234 E-Mail karger@karger.ch www.karger.com www.karger.com/ocl worse overall survival, controlling for stage at initial diagnosis, disease-free survival, and stage at first recurrence [HR = 2.09 (95\% Cl 1.24-3.54), $\mathrm{p}=0.006]$. Conclusions: Our results demonstrate the prognostic relevance of tumor proliferation in recurrent melanoma patients. Data also support restratification of risk assessment upon recurrence that considers tumor biology in addition to clinical variables evaluated as part of the standard of care.

Copyright $\odot 2011$ S. Karger AG, Basel

\section{Introduction}

Most melanoma patients are diagnosed with thin $(\leq 1.00 \mathrm{~mm})$ primaries [1], and their 10-year survival rate is $93 \%$ [2]. The 10 -year survival rate, however, decreases to $9 \%$ in patients who develop a recurrence [3]. Twenty percent of patients with localized melanoma ultimately recur [4]; therefore, it is important to identify prognostic determinants of survival upon recurrence that might influence treatment decisions.

T.J.T. and M.W.M. contributed equally to this paper.
Iman Osman, MD

New York University School of Medicine

522 First Avenue, Smilow 405

New York, NY 10016 (USA)

Tel. +1 212263 9076, E-Mail iman.osman@ nyumc.org 
Previous studies evaluating prognostic factors of survival at recurrence have focused on primary tumor characteristics and first recurrence clinical variables [4-14]. While the prognostic relevance of primary tumor characteristics in recurrent melanoma patients remains unclear $[4,6,7,10,12,13]$, the general consensus is that clinical variables present at recurrence have prognostic value [4-8, 10-14]. Few studies, however, have investigated the prognostic relevance of tumor characteristics at recurrence $[15,16]$ despite their key role in defining prognostic subgroups at primary diagnosis. The importance of examining tumor proliferation has been underscored by the addition of mitotic rate to the 7 th edition of the American Joint Committee on Cancer (AJCC) melanoma staging system [2].

Compared to mitotic rate, the expression level of nuclear antigen Ki-67 may be a better assessment of proliferation since $\mathrm{Ki}-67$ is expressed in mitosis as well as during the G1, S, and G2 phases of the cell cycle in proliferating cells [17]. Ki-67 expression has also been shown to have prognostic value in other cancers (most notably in breast cancer) [18-23]. In breast cancer, Ki-67 expression is a prognostic factor of overall survival, but like HER2 receptor status it has not been universally applied to the clinical management of patients pending further validation [18]. In the current study, we investigated the prognostic relevance of the proliferative index of the recurrent melanoma in a cohort of patients with prospective clinical follow-up.

\section{Methods}

\section{Study Population}

Recurrent melanoma tissues were obtained from patients prospectively enrolled in the Interdisciplinary Melanoma Cooperative Group (IMCG) at New York University (NYU) Medical Center between August 2002 and June 2008 [24]. Demographic and clinicopathologic data were recorded prospectively, and all patients were followed through February 2010. This study was approved by the Institutional Review Board at the NYU School of Medicine (IRB No. 10362), and informed consent was obtained from all patients at the time of enrollment.

\section{Clinicopathologic Variables}

Baseline variables, including age at primary diagnosis, gender, and stage at initial diagnosis, were collected. Stage at initial diagnosis was included in the analysis to control for the effect of primary tumor characteristics. The following clinical variables at recurrence were analyzed: disease-free survival (date of initial diagnosis to date of first recurrence), stage at first recurrence, total number of recurrences, lactate dehydrogenase $(\mathrm{LDH})$ level at first recurrence, and Eastern Cooperative Oncology Group (ECOG) performance status at first recurrence. To ensure uniform collec- tion of LDH levels, only lab results from NYU were utilized. Values above $618 \mathrm{U} / \mathrm{l}$ (normal reference range 313-618 U/l) were considered high.

\section{Assessment of Ki-67 Expression}

Immunohistochemistry was performed using mouse anti-human Ki-67 clone 30-9 (Ventana Medical Systems, Tucson, Ariz., USA) on formalin fixed, paraffin-embedded tissue specimens from patients undergoing metastasectomy for surgically accessible recurrent lesions or from patients who had already undergone metastasectomy within the past 6 months for recurrence with no systemic intervention prior to surgery. Recurrent tissue was obtained from the site of first recurrence when possible. In brief, sections were deparaffinized in xylene (3 changes), rehydrated through graded alcohols (3 changes, 100\% ethanol; 3 changes, $95 \%$ ethanol), and rinsed in distilled water. Heat-induced epitope retrieval was performed in $10 \mathrm{~mm}$ citrate buffer, $\mathrm{pH}$ 6.0, for Ki-67 for $20 \mathrm{~min}$ in a 1,200-watt microwave oven at $90 \%$ power. Sections were allowed to cool for $30 \mathrm{~min}$ and then rinsed in distilled water. Antibody incubations and detection were carried out at $37^{\circ} \mathrm{C}$ on a NexES instrument (Ventana Medical Systems) using Ventana's reagent buffer and detection kits unless otherwise noted. Ki-67 was applied neatly and incubated for $30 \mathrm{~min}$. Primary antibodies were detected with Ventana's biotinylated goat anti-mouse secondary antibody followed by streptavidin-horseradish-peroxidase conjugate. The complex was visualized with Naphthol-ASMX phosphatase and Fast Red complex. Slides were washed in distilled water, counterstained with hematoxylin, dehydrated, and mounted with permanent media. Appropriate positive and negative controls were included with the study sections.

Blinded to patients' clinical data, an attending pathologist (H.Y.) scored Ki-67 expression by the percentage of positivelystained tumor cells on a continuous scale of 1-100. In tumors with focal regions of immunoreactivity, representative averages of positively-stained melanoma cells were recorded. After the scoring of Ki-67 expression in the recurrent tissue, values were categorized as $\leq 25 \%$ (low expression) or $>25 \%$ (overexpression). Since there is no validated cutoff value, ours was set at $25 \%$ as it was previously shown to identify rapidly proliferating tumors [25] and as it was both the mean and the median percentage of Ki-67 expression in this study.

\section{Statistical Analysis}

Complete-case univariate analysis evaluating overall survival was performed for each variable, excluding unavailable data. For binary variables, the estimates of the survival curves were computed using the Kaplan-Meier method, and the differences of these curves were tested with a logrank (Mantel-Haenszel) test. A multivariate Cox proportional hazards regression model was then fitted using the regressors significant on univariate analysis with the most clinical applicability. Hazard ratios (HR) with corresponding 95\% confidence intervals (CI) are reported. All p values reported are 2-sided, with statistical significance evaluated at the 0.05 alpha level. A percentage agreement test in 2 variables calculated the coefficient of concordance. All analyses were performed in $\mathrm{R}$, a language and environment for statistical computing ( $\mathrm{R}$ Foundation for Statistical Computing, Vienna, Austria). 


\section{Results}

264 recurrent melanoma patients were identified in the IMCG database. Fifteen (6\%) patients with incomplete follow-up were excluded. Of the remaining 249 patients, 114 had recurrent tumor specimens available for analysis, and 108 of these $(95 \%)$ were from the site of first recurrence. There was no difference in baseline characteristics (age at primary diagnosis, gender, primary tumor thickness, ulceration, mitotic rate, histological type, and anatomic site) between the patients with available recurrent tissue and those who did not have accessible recurrent tissue (table 1). It is important to note that 18 patient-matched pairs of primary tumors and first recurrence tissues were obtained to examine concordance of Ki-67 expression, but the small sample size prohibited further analysis.

The median age at recurrence in the group of $114 \mathrm{pa}-$ tients with available recurrent tissue was 62 . There were 63 males and 51 females. The majority of patients recurred at stage III $(\mathrm{n}=80,70 \%)$. Twenty-one $(18 \%) \mathrm{pa}$ tients had an unknown primary. The median follow-up time from the date of initial diagnosis to the date of last follow-up was 3.9 years. The median follow-up time was 1.6 years from the date of first recurrence to the date of last follow-up. Forty-six (40\%) patients were alive at last follow-up, and this group had a median overall survival of 5.7 years. The remaining $68(60 \%)$ patients died during the follow-up period, and 66 of these patients died of melanoma. The median overall survival of the whole cohort was 3.9 years, with a 5 -year survival rate of $38 \%$.

\section{Patients Whose Recurrent Tumors Overexpressed}

Ki-67 Had a Shorter Median Overall Survival

All clinicopathologic variables assessed in this study were predictive of overall survival in our cohort of recurrent melanoma patients (table 2). The median overall survival was significantly reduced in patients with advancedstage melanoma at initial diagnosis (stage IV vs. stage I, 0.7 and 9.7 years, respectively; $p<0.001$ ), in patients with a shorter disease-free survival ( $<1$ year vs. $>3$ years, 2.5 and 10.8 years, respectively; $\mathrm{p}<0.001)$, in patients with stage IV disease at recurrence (stage IV vs. stage III, 2.9 and 7.9 years, respectively; $p=0.001$ ), in patients with $\geq 3$ recurrences ( $\geq 3$ vs. 1, 3.0 years vs. insufficient number of deaths to determine median survival, respectively; $\mathrm{p}<$ 0.001), in patients with a high LDH level at first recurrence (high vs. normal, 1.5 and 6.9 years, respectively; $\mathrm{p}=0.03$ ), and in patients with a worse ECOG status at first recurrence (1-2 vs. $0,1.7$ and 10.2 years, respectively; $\mathrm{p}<0.001)$.

Proliferative Index of Recurrent Melanoma
Table 1. Baseline characteristics of recurrent melanoma patients $(\mathrm{n}=249)$

\begin{tabular}{|c|c|c|}
\hline Variable & $\begin{array}{l}\text { Recurrent } \\
\text { tissue not } \\
\text { available } \\
(\mathrm{n}=135)\end{array}$ & $\begin{array}{l}\text { Recurrent } \\
\text { tissue } \\
\text { available } \\
(\mathrm{n}=114)\end{array}$ \\
\hline \multicolumn{3}{|l|}{ Age at primary diagnosis (years) } \\
\hline Median (range) & $62(19-91)$ & $57(15-92)$ \\
\hline$<60$ & $60(44 \%)$ & $61(54 \%)$ \\
\hline$\geq 60$ & $75(56 \%)$ & $53(46 \%)$ \\
\hline \multicolumn{3}{|l|}{ Gender } \\
\hline Male & $80(59 \%)$ & $63(55 \%)$ \\
\hline Female & $55(41 \%)$ & $51(45 \%)$ \\
\hline \multicolumn{3}{|l|}{ Primary tumor thickness (mm) } \\
\hline$\leq 1.0$ & $22(16 \%)$ & $11(10 \%)$ \\
\hline $1.01-4.0$ & $65(48 \%)$ & $65(57 \%)$ \\
\hline$>4.0$ & $29(21 \%)$ & $17(15 \%)$ \\
\hline Unclassified & $3(2 \%)$ & $0(0 \%)$ \\
\hline Unknown primary & $16(12 \%)$ & $21(18 \%)$ \\
\hline \multicolumn{3}{|l|}{ Primary tumor ulceration status } \\
\hline Absent & $64(47 \%)$ & $60(53 \%)$ \\
\hline Present & $53(39 \%)$ & $32(28 \%)$ \\
\hline Unclassified & $2(1 \%)$ & $1(1 \%)$ \\
\hline Unknown primary & $16(12 \%)$ & $21(18 \%)$ \\
\hline \multicolumn{3}{|l|}{$\begin{array}{l}\text { Primary tumor mitotic rate } \\
\left(\text { mitoses } / \mathrm{mm}^{2}\right)\end{array}$} \\
\hline 0 & $11(8 \%)$ & $13(11 \%)$ \\
\hline$\geq 1$ & $98(73 \%)$ & $74(65 \%)$ \\
\hline Unclassified & $10(7 \%)$ & $6(5 \%)$ \\
\hline Unknown primary & $16(12 \%)$ & $21(18 \%)$ \\
\hline \multicolumn{3}{|l|}{ Primary tumor histological type } \\
\hline Superficial spreading melanoma & $38(28 \%)$ & $26(23 \%)$ \\
\hline Nodular melanoma & $55(41 \%)$ & $46(40 \%)$ \\
\hline Acral lentiginous melanoma & $4(3 \%)$ & $6(5 \%)$ \\
\hline Lentigo maligna melanoma & $2(1 \%)$ & $2(2 \%)$ \\
\hline Desmoplastic melanoma & $4(3 \%)$ & $5(4 \%)$ \\
\hline Other & $2(1 \%)$ & $4(4 \%)$ \\
\hline Unclassified & $14(10 \%)$ & $4(4 \%)$ \\
\hline Unknown primary & $16(12 \%)$ & $21(18 \%)$ \\
\hline \multicolumn{3}{|l|}{ Primary tumor anatomic site } \\
\hline Extremity & $48(36 \%)$ & $36(32 \%)$ \\
\hline Axial & $71(53 \%)$ & $57(50 \%)$ \\
\hline Unknown primary & $16(12 \%)$ & $21(18 \%)$ \\
\hline
\end{tabular}

Percentages may not sum to 100 due to rounding numbers.

Patients whose recurrent tumors overexpressed Ki-67 also had a shorter median overall survival (high vs. low Ki-67 expression, 3.6 and 9.5 years, respectively; $\mathrm{p}=0.03$ ) (fig. 1a). High Ki-67 expression was seen in $57(50 \%)$ of the 114 recurrent tissues. Fifty-three (93\%) of the 57 cases were from the site of first recurrence (39 locoregional and 14 distant). Recurrent tissues with low Ki-67 expression were similarly distributed (table 3). A representative case

Oncology 2011;80:181-187 
Table 2. Univariate analysis of clinicopathologic characteristics associated with overall survival in recurrent melanoma patients $(\mathrm{n}=114)$

\begin{tabular}{|c|c|c|c|}
\hline Variable & $\mathrm{n}=114^{\mathrm{a}}$ & $\begin{array}{l}\text { Median } \\
\text { survival } \\
\text { (years) }\end{array}$ & $\begin{array}{l}\mathrm{p} \\
\text { value }^{\mathrm{b}}\end{array}$ \\
\hline Stage at initial diagnosis & & & $<0.001$ \\
\hline I & $31(27 \%)$ & 9.7 & \\
\hline II & $34(30 \%)$ & 7.1 & \\
\hline III & $42(37 \%)$ & 2.7 & \\
\hline IV & $7(6 \%)$ & 0.7 & \\
\hline Disease-free survival (years) & & & $<0.001$ \\
\hline$<1$ & $48(42 \%)$ & 2.5 & \\
\hline $1-3$ & $36(32 \%)$ & 4.8 & \\
\hline$>3$ & $30(26 \%)$ & 10.8 & \\
\hline Stage at first recurrence & & & 0.001 \\
\hline III & $80(70 \%)$ & 7.9 & \\
\hline IV & $34(30 \%)$ & 2.9 & \\
\hline Total number of recurrences & & & $<0.001$ \\
\hline 1 & $25(22 \%)$ & $\mathrm{NA}^{\mathrm{c}}$ & \\
\hline 2 & $19(17 \%)$ & 9.5 & \\
\hline$\geq 3$ & $70(61 \%)$ & 3.0 & \\
\hline $\mathrm{LDH}$ level at first recurrence & & & 0.03 \\
\hline Normal & $50(82 \%)$ & 6.9 & \\
\hline High & $11(18 \%)$ & 1.5 & \\
\hline $\begin{array}{l}\text { ECOG performance status at } \\
\text { first recurrence }\end{array}$ & & & $<0.001$ \\
\hline 0 & $49(82 \%)$ & 10.2 & \\
\hline 1 or 2 & $11(18 \%)$ & 1.7 & \\
\hline $\begin{array}{l}\text { Ki- } 67 \text { expression level in } \\
\text { recurrent tissue }\end{array}$ & & & 0.03 \\
\hline Low $(\leq 25 \%)$ & $57(50 \%)$ & 9.5 & \\
\hline High $(>25 \%)$ & $57(50 \%)$ & 3.6 & \\
\hline
\end{tabular}

${ }^{\text {a }}$ Number of patients may not sum to 114 due to unavailable data (unknown values). ${ }^{\mathrm{b}}$ By logrank test. ${ }^{\mathrm{c}}$ Insufficient deaths to determine median survival.

of Ki- 67 overexpression is displayed in figure $1 \mathrm{~b}, \mathrm{c}$. A negative metastatic lymph node specimen illustrates a representative case of low Ki-67 expression in which a mitotic figure and a germinal center serve as internal positive controls (fig. 1d, e).

\section{A High Proliferative Index in Recurrent Melanoma Is}

Independently Associated with Worse Survival

Stage IV at initial diagnosis, a shorter disease-free survival, stage IV at first recurrence, and a high proliferative index in the recurrent tumor were independently associated with worse overall survival (table 4). Compared to patients with stage I melanoma at initial diagnosis, those with stage IV melanoma had a shorter overall survival
Table 3. Recurrent tissue type by anatomic site $(\mathrm{n}=108)$

\begin{tabular}{lcc}
\hline Anatomic site & $\begin{array}{l}\text { Low Ki-67 } \\
\text { expression } \\
(\mathrm{n}=55)\end{array}$ & $\begin{array}{l}\text { High Ki-67 } \\
\text { expression } \\
(\mathrm{n}=53)\end{array}$ \\
\hline $\begin{array}{l}\text { Locoregional } \\
\text { Local recurrence }\end{array}$ & $2(4 \%)$ & $3(6 \%)$ \\
$\quad$ Regional skin & $10(18 \%)$ & $16(30 \%)$ \\
$\quad$ Regional lymph node & $27(49 \%)$ & $20(38 \%)$ \\
Distant & $2(4 \%)$ & $3(6 \%)$ \\
Distant skin & $1(2 \%)$ & $1(2 \%)$ \\
Distant lymph node & $13(24 \%)$ & $10(19 \%)$ \\
Distant visceral & 4 & 3 \\
$\quad$ Brain & 5 & 2 \\
$\quad$ Lung & 4 & 5 \\
$\quad$ Other & &
\end{tabular}

Percentages do not sum to 100 due to rounding numbers. Includes patients with recurrent tissue from the site of first recurrence only.

Table 4. Multivariate analysis of clinicopathologic variables associated with overall survival in recurrent melanoma patients $(\mathrm{n}=114)$

\begin{tabular}{lrlc}
\hline Variable & HR & $95 \%$ CI & p value \\
\hline Stage at initial diagnosis & & & \\
$\quad$ II vs. I & 1.34 & $0.67-2.66$ & 0.41 \\
$\quad$ III vs. I & 1.97 & $0.98-3.96$ & 0.06 \\
$\quad$ IV vs. I & 15.64 & $4.11-59.53$ & $<0.001$ \\
$\begin{array}{l}\text { Disease-free survival (years) } \\
\quad>3 \text { vs. }<1\end{array}$ & 0.15 & $0.07-0.34$ & $<0.001$ \\
$\quad 1-3$ vs. $<1$ & 0.45 & $0.23-0.86$ & 0.02 \\
$\begin{array}{l}\text { Stage at first recurrence } \\
\quad \text { IV vs. III }\end{array}$ & 2.81 & $1.55-5.09$ & $<0.001$ \\
$\begin{array}{l}\text { Ki-67 expression level in } \\
\text { recurrent tissue }\end{array}$ & & & \\
$\quad>25 \%$ vs. $\leq 25 \%$ & 2.09 & $1.24-3.54$ & 0.006 \\
\hline
\end{tabular}

$(\mathrm{HR}=15.64, \mathrm{p}<0.001)$. Both a disease-free survival greater than 3 years and one lasting 1-3 years were significantly associated with improved overall survival when compared to a disease-free survival of less than 1 year $(\mathrm{HR}=$ $0.15, \mathrm{p}<0.001 ; \mathrm{HR}=0.45, \mathrm{p}=0.02$, respectively). Patients with stage IV melanoma at first recurrence had a much worse prognosis than those who recurred at stage III $(\mathrm{HR}=2.81, \mathrm{p}<0.001)$. High Ki-67 expression in the recurrent tissue was an independent predictor of reduced overall survival $(\mathrm{HR}=2.09, \mathrm{p}=0.006)$. 


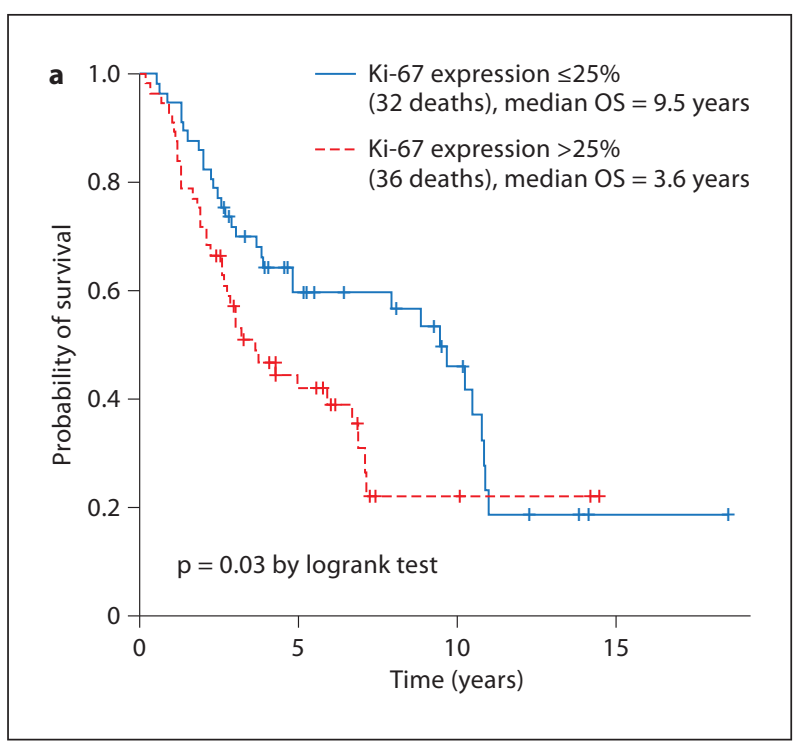

Fig. 1. Evaluation of Ki-67 expression in recurrent melanoma tissue. a Kaplan-Meier curve showing overall survival stratified by expression of Ki-67 in the recurrent melanoma tissue. b A skin metastasis overexpressing Ki-67 demonstrates strong nuclear staining of cells in all phases of the cell cycle (except G0 and early G1). $40 \times$. c High-power $(400 \times)$ view of the inset. Cells in the S
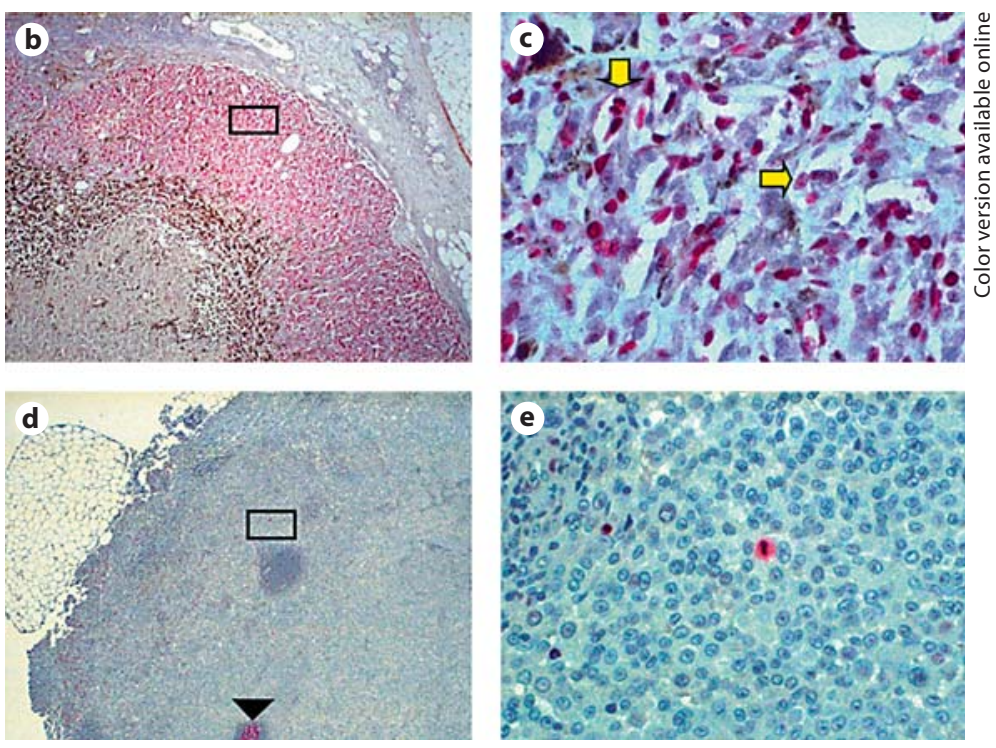

phase (horizontal arrow) and $\mathrm{M}$ phase (vertical arrow) are prominent. d Ki-67 positively stains a germinal center (arrowhead) and a few mitotic figures (inset), serving as internal positive controls in a recurrent lymph node with low Ki-67 expression. $40 \times$. e High-power $(400 \times)$ view of the inset.

\section{Discussion}

Our results underscore the importance of obtaining recurrent melanoma tissue to assess survival probability in recurrent patients. The evolution of tumor biology may underlie the predictive value of a longer disease-free survival in recurrent melanoma patients. First recurrences within 1 year of the primary diagnosis may be more likely to reflect the biological characteristics of the original lesion, whereas the phenotype of a recurrent tumor appearing after an extended period may diverge. Phenotypic changes between the primary and the recurrent tumor have been noted in breast cancer [26,27], emphasizing the importance of investigating both clinical and pathologic variables at recurrence. In the current melanoma paradigm, however, staging at recurrence is based on clinical and radiologic evaluations, such as the LDH level and findings on CT/MRI/PET imaging. Recurrent melanomas are therefore not routinely biopsied, limiting the amount of tissue available for evaluation.

Our data support the prognostic relevance of recurrent tumor proliferation in melanoma patients. Two studies have previously evaluated the prognostic value of $\mathrm{Ki}-67$ expression in recurrent melanoma $[28,29]$. The small sample sizes in these 2 studies $(\mathrm{n}=12$ [28] and $\mathrm{n}=60$ [29]) and the lack of control for first recurrence clinical variables, however, limit the applicability of the results. The limited availability of recurrent tissue likely contributes to the paucity of melanoma studies investigating the prognostic role of Ki-67 expression at recurrence. Instead, the focus has been on the predictive value of primary tumor Ki-67 expression [30, 31], and studies of both thin and thick melanomas have shown a high Ki-67 score to be an independent predictor of reduced overall survival controlling for mitotic rate [30, 31]. Studies of Ki-67 expression in other cancers have similarly concentrated on evaluating its prognostic value at primary diagnosis [19-23]. Two studies in colorectal cancer, however, investigated the prognostic relevance of Ki-67 expression in metastatic tissue from the liver, and both demonstrated that a high Ki-67 score independently predicted worse overall survival $[32,33]$.

An examination of the tissue is especially relevant in melanoma patients with an unknown primary as the prognosis of this group remains unclear. Some studies report improved survival while others find no difference or even decreased survival compared to matched counterparts with known primaries [34-38]. A more robust immune response is thought to underlie the better prognosis of patients with melanoma from an unknown primary since these melanomas may represent metastases from regressed 
lesions and regression is mediated by host immunity. Of the patients in this study with an unknown primary, half of those alive at last follow-up had received immunotherapy (data not shown). In this regard, a recent study by our group [15] demonstrated that an assessment of immune response in the recurrent tissue significantly improved the ability of the current staging system to predict survival in recurrent patients. In particular, a high CD3 count, increased tumor infiltrating leukocytes, and a specific immune response gene signature were all predictive of prolonged survival. The predictive value of the recurrent melanoma mitotic index was also evaluated in this study, and a high mitotic index of the recurrent melanoma was shown to be predictive of reduced survival. Moreover, compared to the 3 aforementioned parameters, the mitotic index of the recurrent tumor was the most significant predictor of survival [15]

Recurrent tumor proliferation has therapeutic implications as well. The Ki-67 index has been shown to be predictive of the immunochemotherapy response in metastatic renal cell carcinoma [39]; therefore, Ki-67 expression in recurrent melanoma may also prove to be similarly predictive. Rapidly proliferating cells are the most frequent target of anti-melanoma treatments as uncontrollable growth is one of the hallmarks of cancer. Melanoma, however, is notoriously chemoresistant [40], and currently available immunotherapies have limited clinical efficacy. A subpopulation of slowly proliferating tumor cells may serve as a continual source of renewal and play a role in non-responders. Recurrent melanomas with a low proliferative index may have an expanded population of these slowly cycling cells, which were recently identified in melanoma cell lines in culture as being characterized by the expression of JARID1B [41]. JARID1B+ melanoma cells not only cycle more slowly but they are also more tumorigenic. Novel therapeutic approaches are therefore needed, combining anti-melanoma drugs which target this subset of slowly proliferating cells and traditional regimens which debulk the tumor of rapidly cycling cells. Chemoresistance in melanoma may be mediated by one of many intrinsic anti-apoptotic mechanisms as well, which in turn affects the relative contribution of proliferation and apoptosis to melanoma progression. NF- $\kappa B$ inhibits both the intrinsic and the extrinsic apoptotic pathways [40], and it is a downstream effector of the RAS/ $R A F / M A P K$ cascade, which is constitutively activated in the majority of melanomas [42, 43]. Constitutive signaling through this pathway results from activating mutations of the oncogene NRAS or BRAF, both of which are common in melanoma $[42,43]$. Mutations in the tumor suppressor gene $p 53$ occur less often, but a downstream target of p53, namely apoptotic activator 1 (Apaf-1), is frequently inactivated in melanoma, impairing p53-induced apoptosis and thus the chemotherapy response [40, 44].

\section{Conclusions}

High Ki-67 expression in recurrent melanoma is predictive of worse overall survival. Our data therefore demonstrate the clinical relevance of assessing tumor biology at recurrence in addition to standard of care variables.

\section{Acknowledgements}

This work was supported by a National Cancer Institute Cancer Center Support Grant (Grant No. 5 P30 CA 016087-27) and the Marc Jacobs Campaign to support the IMCG. The study sponsors had no role in the design of the study; in the collection, analysis, and interpretation of data; in the writing of the manuscript, or in the decision to submit the manuscript for publication.

\section{References}

1 Gimotty PA, Guerry D, Ming ME, Elenitsas R, Xu X, Czerniecki B, Spitz F, Schuchter L, Elder D: Thin primary cutaneous malignant melanoma: a prognostic tree for 10 -year metastasis is more accurate than American Joint Committee on Cancer staging. J Clin Oncol 2004;22:3668-3676.

- 2 Balch CM, Gershenwald JE, Soong SJ, Thompson JF, Atkins MB, Byrd DR, Buzaid AC, Cochran AJ, Coit DG, Ding S, Eggermont AM, Flaherty KT, Gimotty PA, Kirkwood JM, McMasters KM, Mihm MC Jr, Morton DL, Ross MI, Sober AJ, Sondak VK: Final version of 2009 AJCC melanoma staging and classification. J Clin Oncol 2009;27:6199-6206.

\footnotetext{
3 Balch CM, Soong SJ, Smith T, Ross MI, Urist MM, Karakousis CP, Temple WJ, Mihm MC, Barnhill RL, Jewell WR, Wanebo HJ, Desmond R, Investigators from the Intergroup Melanoma Surgical Trial: Long-term results of a prospective surgical trial comparing 2 cm vs. $4 \mathrm{~cm}$ excision margins for 740 patients with 1-4 mm melanomas. Ann Surg Oncol 2001;8:101-108.

4 Francken AB, Accortt NA, Shaw HM, Wiener M, Soong SJ, Hoekstra HJ, Thompson JF: Prognosis and determinants of outcome following locoregional or distant recurrence in patients with cutaneous melanoma. Ann Surg Oncol 2008;15:1476-1484.
}

\footnotetext{
5 Dalal KM, Patel A, Brady MS, Jaques DP, Coit DG: Patterns of first-recurrence and post-recurrence survival in patients with primary cutaneous melanoma after sentinel lymph node biopsy. Ann Surg Oncol 2007;14: 1934-1942.

6 Cohn-Cedermark G, Mansson-Brahme E, Rutqvist LE, Larsson O, Singnomklao T, Ringborg U: Metastatic patterns, clinical outcome, and malignant phenotype in malignant cutaneous melanoma. Acta Oncol 1999;38:549-557.
} 
7 Soong SJ, Harrison RA, McCarthy WH, Urist MM, Balch CM: Factors affecting survival following local, regional, or distant recurrence from localized melanoma. J Surg Oncol 1998;67:228-233.

8 Fusi S, Ariyan S, Sternlicht A: Data on first recurrence after treatment for malignant melanoma in a large patient population. Plast Reconstr Surg 1993;91:94-98.

$\checkmark 9$ Crowley NJ, Seigler HF: Relationship between disease-free interval and survival in patients with recurrent melanoma. Arch Surg 1992;127:1303-1308.

$\checkmark 10$ Reintgen DS, Cox C, Slingluff CL Jr, Seigler HF: Recurrent malignant melanoma: the identification of prognostic factors to predict survival. Ann Plast Surg 1992;28:45-49.

$\checkmark 11$ Markowitz JS, Cosimi LA, Carey RW, Kang S, Padyk C, Sober AJ, Cosimi AB: Prognosis after initial recurrence of cutaneous melanoma. Arch Surg 1991;126:703-708.

-12 Hoyt DJ, Fisher SR: Survival following recurrent malignant melanoma of the head and neck. Laryngoscope 1989;99:586-589.

$\checkmark 13$ Shaw HM, Beattie CW, McCarthy WH, Milton GW: Late relapse from cutaneous stage I malignant melanoma. Arch Surg 1985;120: 1155-1159.

14 Karakousis CP, Temple DF, Moore R, Ambrus JL: Prognostic parameters in recurrent malignant melanoma. Cancer 1983;52:575579.

15 Bogunovic D, O’Neill DW, Belitskaya-Levy I, Vacic V, Yu YL, Adams S, Darvishian F, Berman R, Shapiro R, Pavlick AC, Lonardi S, Zavadil J, Osman I, Bhardwaj N: Immune profile and mitotic index of metastatic melanoma lesions enhance clinical staging in predicting patient survival. Proc Natl Acad Sci USA 2009;106:20429-20434.

>16 Reintgen DS, Vollmer R, Tso CY, Seigler HF: Prognosis for recurrent stage I malignant melanoma. Arch Surg 1987;122:1338-1342.

17 Gerdes J, Schwab U, Lemke H, Stein H: Production of a mouse monoclonal antibody reactive with a human nuclear antigen associated with cell proliferation. Int J Cancer 1983;31:13-20.

-18 Fitzgibbons PL, Page DL, Weaver D, Thor AD, Allred DC, Clark GM, Ruby SG, O’Malley F, Simpson JF, Connolly JL, Hayes DF, Edge SB, Lichter A, Schnitt SJ: Prognostic factors in breast cancer: College of American Pathologists Consensus Statement 1999. Arch Pathol Lab Med 2000;124:966-978.

$\checkmark 19$ Keshgegian AA, Cnaan A: Proliferation markers in breast carcinoma: mitotic figure count, S-phase fraction, proliferating cell nuclear antigen, Ki-67 and MIB-1. Am J Clin Pathol 1995;104:42-49.

-20 Gaglia P, Bernardi A, Venesio T, Caldarola B, Lauro D, Cappa AP, Calderini P, Liscia DS: Cell proliferation of breast cancer evaluated by anti-BrdU and anti-Ki-67 antibodies: its prognostic value on short-term recurrences. Eur J Cancer 1993;29A:1509-1513.
21 Railo M, Nordling S, von Boguslawsky K, Leivonen M, Kyllonen L, von Smitten K: Prognostic value of Ki-67 immunolabelling in primary operable breast cancer. Br J Cancer 1993;68:579-583.

22 Mucci NR, Rubin MA, Strawderman MS, Montie JE, Smith DC, Pienta KJ: Expression of nuclear antigen $\mathrm{Ki}-67$ in prostate cancer needle biopsy and radical prostatectomy specimens. J Natl Cancer Inst 2000;92:19411942.

23 Bettencourt MC, Bauer JJ, Sesterhenn IA, Mostofi FK, McLeod DG, Moul JW: Ki-67 expression is a prognostic marker of prostate cancer recurrence after radical prostatectomy. J Urol 1996;156:1064-1068.

24 Wich LG, Hamilton HK, Shapiro RL, Pavlick A, Berman RS, Polsky D, Goldberg JD, Hernando E, Manga P, Krogsgaard M, Kamino H, Darvishian F, Lee P, Orlow SJ, Ostrer H, Bhardwaj N, Osman I: Developing a multidisciplinary prospective melanoma biospecimen repository to advance translational research. Am J Transl Res 2009;1:35-43.

25 Spyratos F, Ferrero-Pous M, Trassard M, Hacene K, Phillips E, Tubiana-Hulin M, Le Doussal V: Correlation between MIB-1 and other proliferation markers: clinical implications of the MIB-1 cutoff value. Cancer 2002;94:2151-2159.

26 MacFarlane R, Speers C, Masoudi H, Chia S: Molecular changes in the primary breast cancer versus the relapsed/metastatic lesion from a large population based database and tissue microarray series (abstract). J Clin Oncol 2008;26:15s

27 Broglio K, Moulder SL, Hsu L, Kau S, Pusztai L, Symmans WF, Hortobagyi GN, GonzalezAngulo AM, Liedtke C: Prognostic impact of discordance/concordance of triple-receptor expression between primary tumor and metastasis in patients with metastatic breast cancer (abstract). J Clin Oncol 2008;26:15s.

28 Hernberg M, Turunen JP, von Boguslawsky K, Muhonen T, Pyrhönen S: Prognostic value of biomarkers in malignant melanoma. Melanoma Res 1998;8:283-291.

29 Vlaykova T, Talve L, Hahka-Kemppinen M, Hernberg M, Muhonen T, Franssila K, Collan Y, Pyrhönen S: MIB-1 immunoreactivity correlates with blood vessel density and survival in disseminated malignant melanoma Oncology 1999;57:242-252.

30 Gimotty PA, Van Belle P, Elder DE, Murry T, Montone KT, Xu X, Hotz S, Raines S, Ming ME, Wahl P, Guerry D: Biologic and prognostic significance of dermal Ki67 expression, mitoses, and tumorigenicity in thin invasive cutaneous melanoma. J Clin Oncol 2005;23:8048-8056.

31 Ladstein RG, Bachmann IM, Straume O, Akslen LA: Ki-67 expression is superior to mitotic count and novel proliferation markers $\mathrm{PHH} 3, \mathrm{MCM} 4$ and mitosin as a prognostic factor in thick cutaneous melanoma. BMC Cancer 2010;10:140.
32 Petrowsky H, Sturm I, Graubitz O, Kooby DA, Staib-Sebler E, Gog C, Kohne CH, Hillebrand T, Daniel PT, Fong Y, Lorenz M: Relevance of Ki-67 antigen expression and $\mathrm{K}$-ras mutation in colorectal liver metastases. Eur J Surg Oncol 2001;27:80-87.

33 Smith DL, Soria JC, Morat L, Yang Q, Sabatier L, Liu DD, Nemr RA, Rashid A, Vauthey JN: Human telomerase reverse transcriptase (hTERT) and Ki-67 are better predictors of survival than established clinical indicators in patients undergoing curative hepatic resection for colorectal metastases. Ann Surg Oncol 2004; 11:45-51.

>34 Lee CC, Faries MB, Wanek LA, Morton DL: Improved survival for stage IV melanoma from an unknown primary site. J Clin Oncol 2009;27:3489-3495.

35 Lee CC, Faries MB, Wanek LA, Morton DL: Improved survival after lymphadenectomy for nodal metastasis from an unknown primary melanoma. J Clin Oncol 2008;26:535541.

>36 Anbari KK, Schuchter LM, Bucky LP, Mick R, Synnestvedt M, Guerry D 4th, Hamilton R, Halpern AC: Melanoma of unknown primary site: presentation, treatment, and prognosis - a single institution study. Cancer 1997;79:1816-1821

>37 Schlagenhauff B, Stroebel W, Ellwanger U, Meier F, Zimmermann C, Breuninger $\mathrm{H}$, Rassner G, Garbe C: Metastatic melanoma of unknown primary origin shows prognostic similarities to regional metastatic melanoma: recommendations for initial staging examinations. Cancer 1997;80:60-65.

38 Nambisan RN, Alexiou G, Reese PA, Karakousis CP: Early metastatic patterns and survival in malignant melanoma. J Surg Oncol 1987;34:248-252.

39 Papadopoulos I, Rudolph P, Weichert-Jacobsen K, Thiemann O, Papadopoulou D: Prognostic indicators for response to therapy and survival in patients with metastatic renal cell cancer treated with interferon alpha- 2 beta and vinblastine. Urology 1996;48:373-378.

40 Soengas MS, Lowe SW: Apoptosis and melanoma chemoresistance. Oncogene 2003;22: 3138-3151.

-41 Roesch A, Fukunaga-Kalabis M, Schmidt EC, Zabierowski SE, Brafford PA, Vultur A, Basu D, Gimotty P, Vogt T, Herlyn M: A temporarily distinct subpopulation of slow-cycling melanoma cells is required for continuous tumor growth. Cell 2010;141:583-594.

-42 Becker JC, Kirkwood JM, Agarwala SS, Dummer R, Schrama D, Hauschild A: Molecularly targeted therapy for melanoma: current reality and future options. Cancer 2006; 107:2317-2327.

43 Lorigan P, Eisen T, Hauschild A: Systemic therapy for metastatic malignant melanoma - from deeply disappointing to bright future? Exp Dermatol 2008;17:383-394.

44 Dai DL, Martinka M, Bush JA, Li G: Reduced Apaf-1 expression in human cutaneous melanomas. Br J Cancer 2004;91:1089-1095. 